\title{
Optimization of machining parameters of hard porcelain on a CNC machine by Taguchi-and RSM method
}

\author{
Saurabh Agrawal", Manoj kumar Gaur, Dinesh kumar Kasdekar, Sharad Agrawal \\ Department of Mechanical Engineering, Madhav Institute of Technology \& Science, Gwalior, INDIA \\ "Corresponding Author: e-mail:srbh0508@gmail.com.
}

\begin{abstract}
In order to build up a relationship between quality and productivity, the present work focuses an optimized approach to establishing the multi-objective machining parameters and mathematical models for Pressure and Voltage on CNC turning machine (SINUMERIK802D). The Pressure and Voltage seem to be known as quality issues; they are as well presumed to have direct association with productivity. In this study, minimization of response parameters has been identified by using design of experimental methods, Taguchi Analysis and Response surface methodology (RSM). The conduct of experiments was made by employing the Taguchi's $\mathrm{L}_{27}$ Orthogonal array to design the experiment by considering spindle speed (SS), feed rate (FR), angle of cut (AOC) and depth of cut (DOC) as Machining parameters. The model for the Pressure and Voltage, as the function of response parameters, is obtained using the RSM. Finally, the result of developed mathematical model is examined by ANOVA. Experimental results indicate that the feed rate, angle of cut and depth of cut are the leading parameters that affect the Pressure (P). similarly for Voltage (V), all the cutting parameters (Spindle speed, feed rate, angle of cut and depth of cut) are found to be significant, which can be diminished when the significant factors were kept at the lower level, while other factors were kept at the highest level. On the Basis of analysis, it is found that both the optimization techniques predict the results in fair agreement.
\end{abstract}

Keywords:SINUMERIK802D, Machining parameters, RSM, Taguchi Method, ANOVA.

DOI: http://dx.doi.org/10.4314/ijest.v10i1.2

\section{Introduction}

Turning, as a machining technique is a key necessary route to shaping metals and is promoted to higher levels due to its extensive array of operating situations. Conventional turning, weighed against hard turning, exhibits outstanding characteristics that differentiate them from each other. Today's market structure is characterized by players attempting to organize their manufacturing processes to achieve either the utmost quality or the least cost possible in the sales of their products to customers. By taking a close look at the quality aspect of machining operations, the two factors of pressure and voltage are two prominent dictators of quality for the attainment of enhanced quality for machining activities and in the broad array of functionalities in the machining industries (Wang et al, 2010). The need for careful consideration of pressure and quality factors is further dictated by customer needs for superior product quality. The customers' demand stands out as a characteristic carried out at enhancing the mechanical parts accomplishment and the cost of production for products (Asilturk et al., 2012).

Process modelliing as well as optimization are two major problems of manufacturing products. Processes in manufacturing have the general characteristics of exhibiting variables that are interfacing dynamically (Mahapatra et al, 2006). Recently, diverse substantial benefits have been recognized in the machine tool industry as well as in cutting tools. A lot of surface roughness models and simulation packages as well as systems of optimization were built up through the use of diverse cutting factors as well as approaches to optimisation. A number of literature backups for the research are given below.

Latha et al.'s (2010) focus was to calculate drilled composite's surface roughness with the application of fuzzy logic rule-rooted modeling as well as analyses rooted in ANOVA. The CNC drilling machine aided the conduct of the experiment. Collection of surface roughness' data was made subjected to diverse sequence of spindle speeds, drill diameters as well as feed rates. The authors discovered a reasonable concurrence between the model outcome as well as values from experiments. 
The surface response approach was the tool of investigation by Palanikumar et al. (2010) in modeling the factor of delamination as well the parameter referred to as surface roughness, applied to GFRP composites. A three-factor, five-level central composite design was prominently applied in the research. This was coupled with the research. This was coupled with the outcome of analysis of variance, which declared the adequacy of the built-up models at 95\% confidence level, in the range of the factors under consideration. Furthermore, Sun et al. (2005) studied the impact of design variables as well as the various design situations, for instance, objective function as well as restrictions on rotor enactment. The primary tools used were the response surface methodology rootedin the D-optimal 3-level factorials as well as the genetic algorithm with the intent of achieving the most favourable outcome for a specified objective function, embracing the penalty items of limitations.

The wiper inserts seem to have attracted huge interests within the last few years and the influence on surface roughness was elaborated by Correia et al. (2011) in turning activities. Through the employment of wiper inserts and elevated feed rate, surface machined with values $\mathrm{Ra}<0.8 \mathrm{~mm}$ was attained. The pressure $(\mathrm{p})$ and voltage $(\mathrm{v})$ were recognized as quality terms and there is a presumption that they have a straight forward association with the accomplishment of mechanical sections (Liveira at al. 2009). Besides quality, the productivity criterion has a direct relationship with profitability as well as the organization's goodwill. As a result of these proposed reasons, activities in research have been targeted towards obtaining the optimal situations and achieve the intended machining outcome.

The prominent objective of the current investigation is to establish an efficient method of determining the optimal machining parameter (spindle speed, feed rate, angle of cut, depth of cut) for multiple quality characteristics by using the Pressure and Voltage values ( $\mathrm{P}$ and $\mathrm{V}$ ) as multi-objective functions via Taguchi method and Response surface methodology for CNC turned hard porcelain.

\section{Experimental details}

From the review of literature as well as the perception of material specification, a final judgement to utilize four machining parameters was made. The judgement also entails the choice of the corresponding levels for the experiments. The finally selected parameters are the spindle speed, (SS), the feed rate, (FR) as well as the angle-of-art, abbreviated as (AOC). It also involves the depth-of-cut, abbreviated as DOC. Taguchi's $\mathrm{L}_{27}$ orthogonal array in the design of experiment technique has been employed to conduct the experimental matrix. All the input parameters that are spindle speed (SS), feed rate (FR), angle of cut (AOC) and depth of cut (DOC) with three level each and then $3 \times 3 \times 3 \times 3=81$ runs were required in the experiment for four input parameters. But Taguchi's orthogonal array approach reduced number of experimental run to 27 experiments from 81 experiments. All the experiments were conducted on CNC Vertical Turning machine (SINUMERIK802D). The experimental conditions have been given in the Table1.

Table 1. Cutting parameters and their levels.

\begin{tabular}{|c|c|c|c|c|c|}
\hline Symbol & Factors & Units & Level 1 & Level 2 & Level 3 \\
\hline SS & Spindle speed & $\mathrm{m} / \mathrm{min}$. & 200 & 250 & 300 \\
\hline FR & Feed rate & $\mathrm{mm} / \mathrm{rev}$ & 7 & 9 & 11 \\
\hline AOC & Angle of cut & Degree & 0 & 5 & 10 \\
\hline DOC & Depth of cut & $\mathrm{Mm}$ & 2.5 & 3.0 & 3.5 \\
\hline
\end{tabular}

\subsection{Material:}

For the current experiments, the hard porcelain is the experimental material of interest and it arose from joining quarts powder with feldspar powder as well as kaolin with the diverse compositions of chemicals. An analysis involving the material that was machined was conducted through an appropriate application of instruments at diverse values with respect to the need. The specimen's dimensions are $3000 \mathrm{~mm}$ length and $400 \mathrm{~mm}$ diameter.

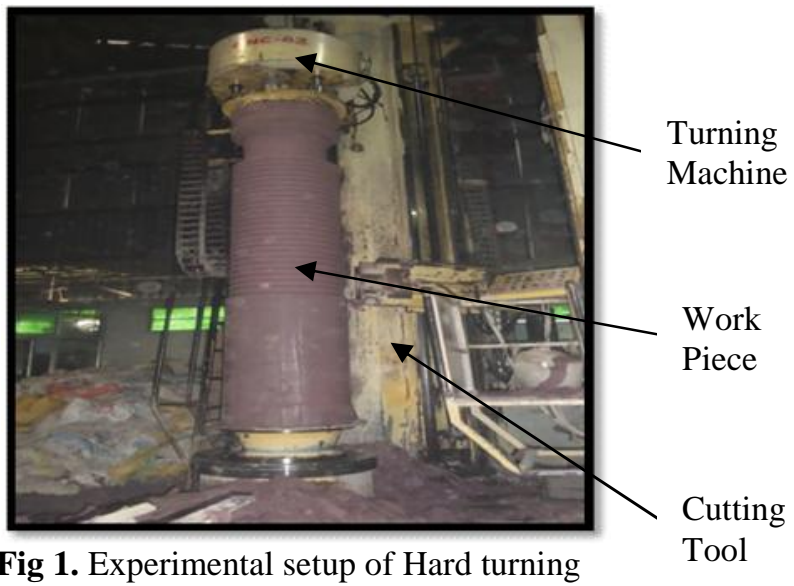


The chemical composition of clay specimen is given below in Table 2. The cutting tool used is made up of $\mathrm{Al}_{2} \mathrm{O}_{3}\left(\mathrm{R}_{7} \cdot 5,10^{0}\right)$. Cutting tool dimensions is $15 \mathrm{~mm}$ OD and $10^{\circ}$ Angle. The machining operations are taken as per the conditions given by the design matrix randomly so as to avoid the mathematical errors. The material and turning machine used in this study is shown in Fig.1. The Pressure $(\mathrm{P})$ and Voltage $(\mathrm{V})$ of the machine test specimen are measured using pressure gauge and KV meters respectively.

Table 2.Chemical composition of the material

\begin{tabular}{|c|c|c|c|c|c|}
\hline Chemical & $\mathrm{SiO}_{2}$ & $\mathrm{Al}_{2} \mathrm{O}_{3}$ & $\mathrm{KNO}_{2}$ & $\begin{array}{c}\mathrm{LiO} \\
\text { (loss on } \\
\text { ignition) }\end{array}$ & $\begin{array}{c}\mathrm{Fe} \\
\text { (Iron) }\end{array}$ \\
\hline $\begin{array}{l}\text { Quartz } \\
\text { Powder }\end{array}$ & $99.5 \%$ & $0.5 \%$ & NIL & NIL & NIL \\
\hline Feldspar & $70 \%$ & $15 \%$ & $15 \%$ & NIL & NIL \\
\hline Ball clay & $70 \%$ & $15 \%$ & NIL & $12 \%$ & $3 \%$ \\
\hline Kaolin & $67 \%$ & $18 \%$ & NIL & $10 \%$ & $5 \%$ \\
\hline
\end{tabular}

\section{Methodology}

\subsection{Response surface methodology}

The RSM is a very popular technique to the optimization of systems whereby input parameter, sometimes known as the independent variables are recognized. The values of these independent variables are derived from physical experiments. They could also be derived from experimental observations as well as simulation experiments. The formulated models have the requirement of being statistically analyzed so as to determine their suitableness. After this, they could be employed to optimize the critical representation. The RSM as well computes the association between the input parameters as well as the attained response surface (Aloufi et al, 2011).This whole procedure includes six steps which are shown in Fig 2 (Aouici et al, 2011).

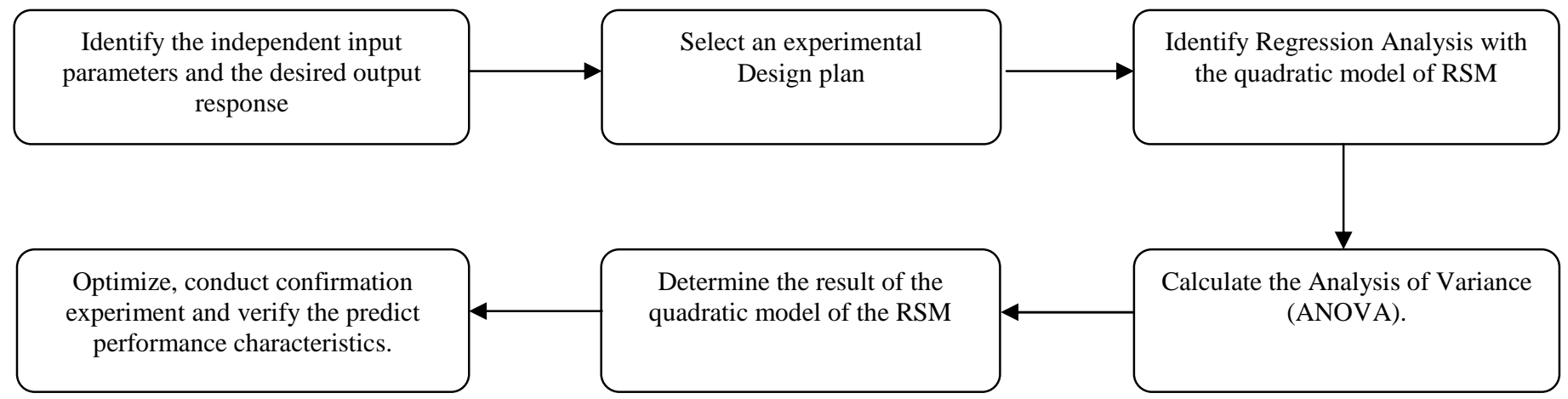

Fig2. Processed step of Response surface methodology

For the present research, the association occurring between the input parameters as well as the output parameters, X, stated as the features of machinability is expressed below. However, the inputs are the feed-rate (FR), the spindle speed (SS) as well as the angle-of-cut (AOC) while the output are the Pressure (P) and Voltage (V).

$$
\mathrm{X}=(\mathrm{SS}, \mathrm{FR}, \mathrm{AOC}, \mathrm{DOC})
$$

where represents the response function. At best, a functional association occurs between the input as well as output variables. The association could be revealed from the perspective of a second-order polynomial equation that is expressed as follows (Kathleen et al., 2004; Myers et al., 2009):

$$
\mu=P_{0}+\sum_{a=1}^{r} P_{a} Q_{a}+\sum_{a=1}^{r} P_{a a} Q_{a}^{2}+\sum a \sum b P_{a b} Q_{a} Q_{b}+\gamma
$$


Where $\mu$ is the estimate response (Pressure and Voltage), $\mathrm{P}_{\mathrm{o}}$ is constant, $\mathrm{P}_{\mathrm{a}}, \mathrm{P}_{\mathrm{aa}}$ and $\mathrm{P}_{\mathrm{ab}}$ represent the linear, quadratic and crossproduct terms coefficients respectively. $\mathrm{Q}$ represents the coded variables.

\subsection{Taguchi design}

Taguchi method is an efficient and powerful designing experiment technique and is widely used for engineering analysis. It reduces the number of tests by using suitable orthogonal arrays and increase process performance and also reduces the effect of factors that cannot be controlled. It improves the rework cost, cycle time cost and manufacturing cost in processes. The Taguchi method is used to find out the optimal values of the objective function in manufacturing processes. Taguchi method makes use of suitable design of orthogonal arrays (OA) to identify the quality characteristics within a minimum set of experiments as compared to other traditional experiment design technique of optimization. OA based experimental results are then transformed into $\mathrm{S} / \mathrm{N}$ ratio to find out the performance characteristics. Therefore, Taguchi method focuses on the effect of variance on quality characteristics instead of an average. The optimum parameter conditions are then resolute by performing the parameter design(Liu et al, 2010).The process step of Taguchi method is illustrated in fig 3 below (Park, 1998):

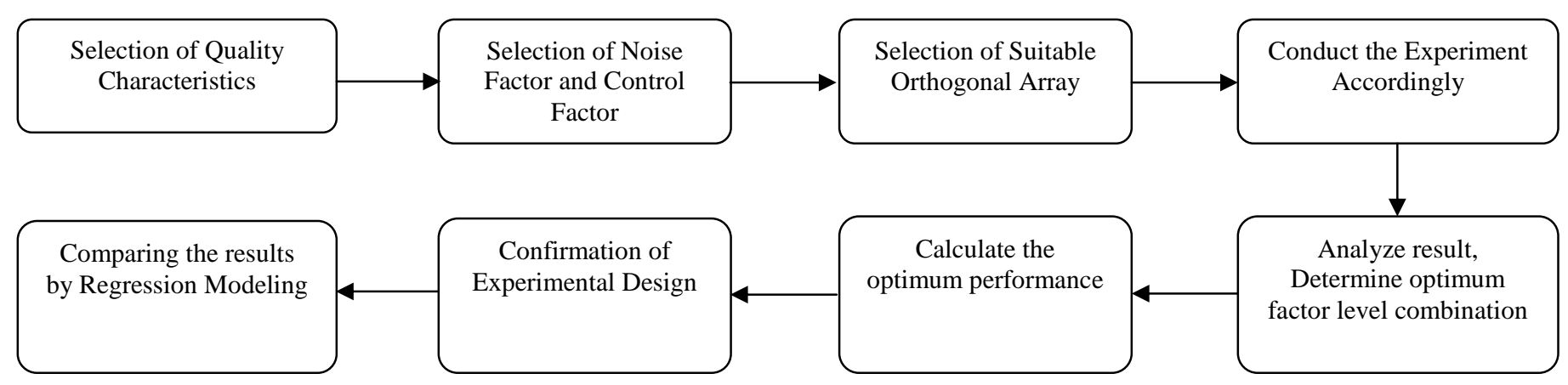

Fig3. Process step of Taguchi Method

Taguchi method for robust design has a wide range of powerful tools. Two major tools that can be used in robust design are $\mathrm{S} / \mathrm{N}$ ratio and orthogonal array. Robust design is a significant aspect that can improve product or manufacturing process design by making the output response insensitive (robust) to variations that can be difficult to be controlled. There are number of quality characteristics involved in robust design, some of them are smaller-the-better, nominal-the-better, higher-the-better. Since the Pressure and Voltage should be minimum from the point of view of improving the quality of product, so the smaller-the-better type S/N ratio has been used in this study (Rose, 2005).

\section{Results and Discussion}

The observed values of Pressure $(\mathrm{P})$ and Voltage $(\mathrm{V})$ for each run are recorded in Table 3. The analysis of results was computed by using software MINITAB 17.

\subsection{Optimization with Taguchi method}

For the current investigation, the method of Taguchi is employed in the establishment of the most advantageous turning parameters. The orthogonal arrays' configuration relies on the level of freedom for the objective function. An appropriate array is the $\mathrm{L}_{27}$ (standard three degree orthogonal array) and it requires 27 runs. Design matrix for each 27 trials is represented in Table3 along with their experimentally measured values.

Analysis of variance of each factor (SS, FR, AOC, DOC) on Pressure and Voltage has been achieved with so-called mean response table. The response of mean values for $\mathrm{P}$ and $\mathrm{V}$ has been shown in Table 4 and 5 respectively. The Table 4 and 5 clearly shows the mean values of control factor at each level and how it is changed while changing the settings of each control factor at each level. Bold values indicate the smaller-is-better characteristics at each level of all the factors(Suhail et al, 2010). 
Table 3. $\mathrm{L}_{27}$ orthogonal array. Experimental results and their $\mathrm{S} / \mathrm{N}$ ratios

\begin{tabular}{|c|c|c|c|c|c|c|}
\hline \multirow[t]{2}{*}{ Exp. No. } & \multicolumn{4}{|c|}{ Control factors level } & \multirow{2}{*}{$\begin{array}{l}\text { Pressure } \\
\text { (P) }\end{array}$} & \multirow{2}{*}{$\begin{array}{l}\text { Voltage } \\
\text { (V) }\end{array}$} \\
\hline & $\begin{array}{c}\text { Spindle speed } \\
\text { (SS) }\end{array}$ & Feed rate (FR) & $\begin{array}{l}\text { Angle of cut } \\
\text { (AOC) }\end{array}$ & $\begin{array}{l}\text { Depth of cut } \\
\text { (DOC) }\end{array}$ & & \\
\hline 1. & 200 & 7 & 5 & 3.0 & 17.0 & 44.0 \\
\hline 2. & 300 & 7 & 5 & 3.0 & 20.4 & 45.2 \\
\hline 3. & 200 & 11 & 5 & 3.0 & 20.9 & 45.5 \\
\hline 4. & 300 & 11 & 5 & 3.0 & 21.5 & 47.4 \\
\hline 5. & 250 & 9 & 0 & 2.5 & 9.3 & 44.2 \\
\hline 6. & 250 & 9 & 10 & 2.5 & 17.6 & 45.4 \\
\hline 7. & 250 & 9 & 0 & 3.5 & 17.4 & 45.7 \\
\hline 8. & 250 & 9 & 10 & 3.5 & 21.2 & 47.9 \\
\hline 9. & 200 & 9 & 5 & 2.5 & 17.8 & 44.5 \\
\hline 10. & 300 & 9 & 5 & 2.5 & 20.2 & 45.6 \\
\hline 11. & 200 & 9 & 5 & 3.5 & 20.4 & 45.9 \\
\hline 12. & 300 & 9 & 5 & 3.5 & 21.2 & 48.2 \\
\hline 13. & 250 & 7 & 0 & 3.0 & 18.0 & 44.8 \\
\hline 14. & 250 & 11 & 0 & 3.0 & 20.1 & 46.1 \\
\hline 15. & 250 & 7 & 10 & 3.0 & 20.7 & 46.4 \\
\hline 16. & 250 & 11 & 10 & 3.0 & 21.5 & 47.1 \\
\hline 17. & 200 & 9 & 0 & 3.0 & 17.5 & 44.9 \\
\hline 18. & 300 & 9 & 0 & 3.0 & 17.8 & 46.5 \\
\hline 19. & 200 & 9 & 10 & 3.0 & 22.0 & 46.2 \\
\hline 20. & 300 & 9 & 10 & 3.0 & 22.2 & 48.0 \\
\hline 21. & 250 & 7 & 5 & 2.5 & 16.9 & 45.0 \\
\hline 22. & 250 & 11 & 5 & 2.5 & 20.1 & 46.6 \\
\hline 23. & 250 & 7 & 5 & 3.5 & 17.9 & 45.1 \\
\hline 24. & 250 & 11 & 5 & 3.5 & 22.1 & 48.4 \\
\hline 25. & 200 & 7 & 0 & 2.5 & 10.0 & 43.0 \\
\hline 26. & 200 & 7 & 10 & 3.5 & 21.2 & 46.9 \\
\hline 27. & 250 & 9 & 5 & 3.0 & 22.5 & 45.0 \\
\hline
\end{tabular}

Table 4.

Response table for means for Pressure (P)
Table 5.

Response table for means for Voltage (V)

\begin{tabular}{|c|c|c|c|c|}
\hline Level & SS & FR & AOC & DOC \\
\hline 1. & $\mathbf{1 8 . 3 5}$ & $\mathbf{1 7 . 7 6}$ & $\mathbf{1 5 . 7 3}$ & $\mathbf{1 5 . 9 9}$ \\
2. & 18.87 & 19.01 & 19.92 & 20.16 \\
3. & 20.55 & 21.03 & 20.91 & 20.20 \\
\hline
\end{tabular}

\begin{tabular}{|c|c|c|c|c|}
\hline Level & SS & FR & AOC & DOC \\
\hline 1. & $\mathbf{4 5 . 1 1}$ & $\mathbf{4 5 . 0 5}$ & $\mathbf{4 5 . 0 3}$ & $\mathbf{4 4 . 9 0}$ \\
2. & 45.98 & 46.00 & 45.88 & 45.93 \\
3. & 46.82 & 46.85 & 46.84 & 46.87 \\
\hline
\end{tabular}

\subsubsection{Main effect plots analysis}

Each control factor's influence could be vividly revealed in Figure 4 and 5, respectively, through response charts. The charts assists in locating the ideal parameters of machining (the level having the superior point on the charts) and to locate the influence of each parameter on mean value (the general slop of the line). The line in Figure 4 and 5, which connect between the levels can clearly show the powerful impact of each control factor. The main effects plots are used to conclude the optimal cutting conditions to obtain the optimum value of output. Figure 4 shows the main effect plot for work piece Pressure $(\mathrm{P})$. The results showed that with the increase in spindle speed there is slight increment in pressure (P) value up to $300 \mathrm{~m} / \mathrm{min}$. The lowest pressure value obtained at $200 \mathrm{~m} / \mathrm{min}$. As the feed increases from $7 \mathrm{~mm} / \mathrm{rev}$ to $11 \mathrm{~mm} / \mathrm{rev}$ the pressure (P) is increased continuously. Angle of cut increases from 0 to 10 degree, the pressure is increased and lowest value obtained at 0 degree. As the depth of cut varies from 2.5 to $3.5 \mathrm{~mm}$. the value of pressure increased and lowest value is obtained at $2.5 \mathrm{~mm}$. Similarly Figure 5 shows the main effect plot for work piece Voltage (V). As the value of input parameters (spindle speed, feed rate, angle of cut and depth of cut) increases the voltage (V) value. Lowest values obtained at $200 \mathrm{~m} / \mathrm{min}, 7 \mathrm{~mm} / \mathrm{rev} ., 0$ degree and $2.5 \mathrm{~mm}$. The Analysis of the results from the plots, used to find out the optimal setting levels of process parameters. Hence, the combination of process parameters SS1-FR1AOC1-DOC1 gives the minimum response value when taking Pressure as output. Similarly, the combination of process parameters SS1-FR1-AOC-DOC1 produces minimum response value when taking Voltage as output. 


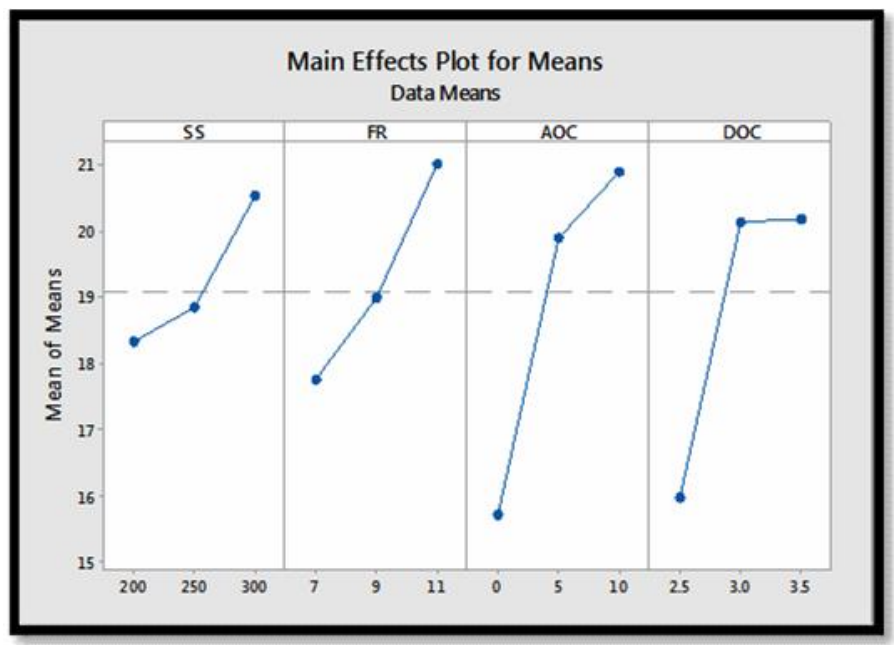

Fig 4. Variation of Mean for input parameters at different levels for pressure

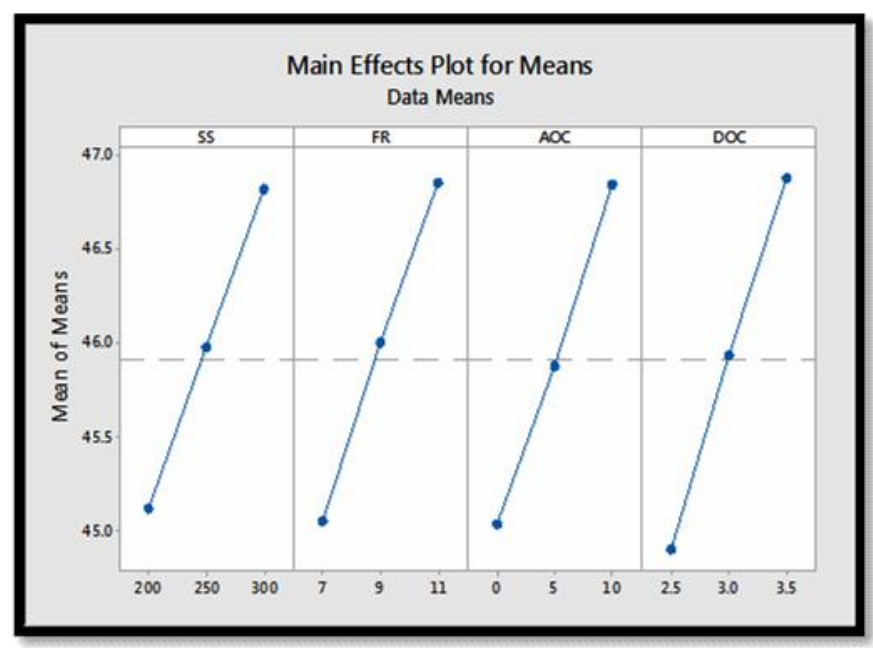

Fig 5.Variation of Mean for input parameters at different levels for voltage

\subsubsection{Analysis of variance (ANOVA)}

The application of ANOVA is made to establish the prominent process parameters in a more precise manner through researching into the comparative significance of process parameters (Ross, 1996). The Table 6 reveals the outcome of the ANOVA for P. It is observed that feed rate (12.64\%), angle of cut $(36.31 \%)$ and depth of cut $(25.09 \%)$ have significant effect on Pressure while the changes in the range of spindle speed given in table 6 have insignificant effect. A bigger F-value reveals the greater influence on the machining accomplishment behaviours (Ross, 1996). Larger F-values are observed for angle of cut and depth of cut. In case of Voltage (V), (From Table 7), all the cutting parameters (spindle speed, feed rate, angle of cut and depth of cut) have significant effect on Voltage.

Table 6.Analysis of variance for $\mathrm{P}$

\begin{tabular}{|c|c|c|c|c|c|l|}
\hline Source & DF & Adj SS & Adj MS & F- Value & P- Value & PC $(\%)$ \\
\hline SS & 2 & 4.751 & 2.375 & 0.79 & 0.470 & 6.41 \\
FR & 2 & 21.410 & 10.705 & 3.55 & 0.050 & 12.64 \\
AOC & 2 & 93.071 & 46.536 & 15.44 & 0.000 & 36.31 \\
DOC & 2 & 69.639 & 34.820 & 11.55 & 0.001 & 25.09 \\
Error & 18 & 54.253 & 3.014 & & & \\
Total & 26 & 277.547 & & & & \\
\hline
\end{tabular}

Table 7.Analysis of variance for $\mathrm{V}$

\begin{tabular}{|c|c|c|c|c|c|l|}
\hline Source & DF & Adj SS & Adj MS & F- Value & P- Value & PC (\%) \\
\hline SS & 2 & 8.969 & 4.4846 & 14.36 & 0.000 & 20.89 \\
FR & 2 & 10.214 & 5.1068 & 16.36 & 0.000 & 18.38 \\
AOC & 2 & 9.729 & 4.8645 & 15.58 & 0.000 & 25.46 \\
DOC & 2 & 11.391 & 5.6957 & 18.24 & 0.000 & 23.61 \\
Error & 18 & 5.620 & 0.3122 & & & \\
Total & 26 & 48.239 & & & & \\
\hline
\end{tabular}

\subsubsection{Prediction of optimal design}

Subsequent to choosing the most favourable setting of machining parameters, the concluding action is to calculate and confirm the enhancement of the accomplishment behaviour by employing the most favourable setting of machining parameters. The 
approximate significance of pressure (P) employing the most favourable parametric setting could be computed as (Maiyar et al, 2013):

$$
\widehat{\gamma}=\gamma_{m}+\sum_{i=1}^{q} \mathbb{l}\left(\bar{\gamma}_{j}-\rrbracket \gamma_{m}\right)
$$

Where $\gamma_{\mathrm{m}}$ is the total mean of the pressure (P), $\bar{\gamma}_{j}$ is the mean of the pressure $(\mathrm{P})$ at the optimum level and $\mathrm{q}$ is the number of cutting parameters that significantly affects the multiple performance characteristics.

The estimated mean of the Pressure P can be computed as:

$$
\begin{aligned}
\hat{\gamma} & =19.088+[(18.35-19.088)+(17.76-19.088)+(15.73-19.088)+(15.99-19.088)] \\
& =19.088+[-0.738-1.328-3.358-3.098]=19.088-8.522=10.566 \mathrm{~kg} / \mathrm{cm}^{2}
\end{aligned}
$$

Where, $\gamma_{m}=19.088$ was calculated from Table 3

Likewise, estimated mean of the Voltage V can be computed as:

$$
\begin{aligned}
\widehat{\gamma} & =45.907+[(45.11-45.907)+(45.05-45.907)+(45.03-45.907)+(44.90-45.907)] \\
& =45.907+[-0.797-0.857-0.877-1.007]=45.907-3.538=42.369 \mathrm{kv}
\end{aligned}
$$

Based on the calculated values shown above, it is clear that the predicted value for pressure $\left(10.566 \mathrm{~kg} / \mathrm{cm}^{2}\right)$ is larger than the experimental value $\left(10 \mathrm{~kg} / \mathrm{cm}^{2}\right)$ and the percentage of error is $0.0056 \%$. Likewise, the predicted value for voltage $(42.369 \mathrm{kv})$ is smaller than the experimental value $(43.0 \mathrm{kv})$ and the percentage of error is $0.0063 \%$.

\subsection{Optimization with Response Surface Methodology (RSM)}

The sufficiency of the response surface quadratic model was further examined through ANOVA and results are presented in Table 8 and 9. From the table 8, it is clear that the first-order of angle of cut (AOC) and depth of cut (DOC) have significant effect on Pressure P. On the other- end, from the Table 9, it is clear that the first order of spindle speed (SS), feed rate (FR), angle of cut (AOC) and depth of cut (DOC) have significant effect on Voltage (V). Quadratic and pairwise interactions of SS, FR, AOC, and DOC have no significant effect on the response parameters.

Table 8.

ANOVA of quadratic response surface design for $\mathrm{P}$

\begin{tabular}{|c|c|c|c|c|c|}
\hline Source & DF & Adj SS & Variance & $\begin{array}{c}\text { F- } \\
\text { Value }\end{array}$ & $\begin{array}{c}\text { P- } \\
\text { Value }\end{array}$ \\
\hline SS & 1 & 3.383 & 3.3835 & 0.90 & 0.360 \\
FR & 1 & 16.594 & 16.5944 & 4.44 & 0.057 \\
AOC & 1 & 59.253 & 59.2526 & 15.84 & 0.002 \\
DOC & 1 & 32.303 & 32.3032 & 8.63 & 0.012 \\
SS*SS & 1 & 0.107 & 0.1073 & 0.03 & 0.868 \\
FR*FR & 1 & 0.021 & 0.0205 & 0.01 & 0.942 \\
AOC*AOC & 1 & 10.429 & 10.4291 & 2.79 & 0.121 \\
DOC*DOC & 1 & 16.535 & 16.5352 & 4.42 & 0.057 \\
SS*FR & 1 & 0.516 & 0.5157 & 0.14 & 0717 \\
SS*A0C & 1 & 0.288 & 0.2883 & 0.08 & 0.786 \\
SS*DOC & 1 & 1.824 & 1.8236 & 0.49 & 0.498 \\
FR*AOC & 1 & 1.411 & 1.4106 & 0.38 & 0.551 \\
FR*DOC & 1 & 0.004 & 0.0036 & 0.00 & 0.976 \\
AOC*DOC & 1 & 2.617 & 2.6169 & 0.70 & 0.419 \\
Error & 12 & 44.896 & 3.7413 & & \\
Total & 26 & 277.54 & & & \\
\hline
\end{tabular}

Table 9.

ANOVA of quadratic response surface design for $\mathrm{V}$

\begin{tabular}{|c|c|c|c|c|c|}
\hline Source & DF & Adj SS & Variance & $\begin{array}{c}\text { F- } \\
\text { Value }\end{array}$ & $\begin{array}{c}\text { P- } \\
\text { Value }\end{array}$ \\
\hline SS & 1 & 9.07 & 9.079 & 23.40 & 0.000 \\
FR & 1 & 10.3619 & 10.3619 & 26.70 & 0.000 \\
AOC & 1 & 7.7674 & 7.7674 & 20.02 & 0.001 \\
DOC & 1 & 9.6895 & 9.6895 & 24.97 & 0.000 \\
SS*SS & 1 & 0.3261 & 0.3261 & 0.84 & 0.377 \\
FR*FR & 1 & 0.2426 & 0.2426 & 0.63 & 0.444 \\
AOC*AOC & 1 & 0.8300 & 0.8300 & 2.14 & 0.169 \\
DOC*DOC & 1 & 0.5299 & 0.5299 & 1.37 & 0.265 \\
SS*FR & 1 & 0.0343 & 0.0343 & 0.09 & 0.771 \\
SS*AOC & 1 & 0.0494 & 0.0494 & 0.13 & 0.727 \\
SS*DOC & 1 & 0.1024 & 0.1024 & 0.26 & 0.617 \\
FR*AOC & 1 & 0.4306 & 0.4306 & 1.11 & 0.313 \\
FR*DOC & 1 & 0.3494 & 0.3494 & 0.90 & 0.361 \\
AOC*DOC & 1 & 0.1183 & 0.1183 & 0.30 & 0.591 \\
Error & 12 & 4.6585 & 0.3881 & & \\
Total & 26 & & & & \\
\hline
\end{tabular}

Box-Behnken design was used to develop relation between the machining parameters and response parameters $\mathrm{P}$ and $\mathrm{V}$. The equations that are expressed subsequently represent the ultimate empirical representations of the Response parameters. 
$>$ The optimal combination of process parametersbased on Taguchi analysis for obtaining minimum response values for both Pressure (P)and Voltage (V) is: $\mathrm{SS}_{1}$ (spindle speed $200 \mathrm{~m} / \mathrm{min}$ ), $\mathrm{FR}_{1}$ (feed rate $7 \mathrm{~mm} / \mathrm{rev}$.), $\mathrm{AOC}_{1}$ (angle of cut 0 degree), $\mathrm{DOC}_{1}$ (depth of cut $2.5 \mathrm{~mm}$ ).

$>$ The optimal combination of process parametersbased on Response Surface Methodology (RSM) for both Pressure (P) and Voltage $(\mathrm{V})$ is: $\mathrm{SS}_{1}$ (spindle speed $200 \mathrm{~m} / \mathrm{min}$ ), $\mathrm{FR}_{1}$ (feed rate $7 \mathrm{~mm} / \mathrm{rev}$.), $\mathrm{AOC}_{1}$ (angle of cut 0 degree), $\mathrm{DOC}_{1}$ (depth of cut $2.5 \mathrm{~mm}$ ).

$>$ In Taguchi statistical analysis, the ANOVA revealed that thefeed rate (FR), angle of cut (AOC) and depth of cut (DOC) are thedominant parameters for Pressure $(\mathrm{P})$ with the percentage contribution of $12.64 \%, 36.31 \%$ and $25.09 \%$ respectively. Similarly in case of Voltage (V), all the input parameters (SS, FR, AOC and DOC) have significant effect with the percentage contribution of $20.89 \%, 18.38 \%, 25.46 \%$ and $23.61 \%$ respectively in bringing down the average response value.

$>$ In Response Surface Methodology (RSM), the ANOVA revealed that angle of cut (AOC) and depth of cut (DOC) are the dominant parameters for Pressure (P) with the percentage contribution of $33.91 \%$ and $15.53 \%$ respectively. Similarly in case of Voltage (V), all the input parameters (SS, FR, AOC and DOC) have significant effect with the percentage contribution of $20.89 \%, 18.22 \%, 23.88 \%$ and $21.72 \%$ respectively in bringing down the average response value.

$>$ Based on prediction of optimal design applied in Taguchi analysis, the predicted value for pressure is $10.566 \mathrm{~kg} / \mathrm{cm}^{2}$ and predicted value for voltage is $42.369 \mathrm{kv}$.

$>$ Based on prediction of optimal design applied in Response Surface Methodology (RSM), the predicted value for pressure is $9.723 \mathrm{~kg} / \mathrm{cm}^{2}$ and predicted value for voltage is $43.480 \mathrm{kv}$.

$>$ The experimental and computational efforts needed to optimize these parameters. It was illustrated that both the methods (Taguchi Analysis and RSM) was efficient and effective for multi-attribute decision making problem in Hard Turning.

\section{References}

Aggarwal A., Singh H., Kumar P., Singh M., 2008. Optimizing power consumption for CNC turned parts using response surface methodology, Taguchi's technique - a comparative analysis, Journal of Materials Processing Technology, Vol. 200, pp. 373384.

Aloufi M., Kazmierski T.J., 2011. A response surface modelling approach to performance optimisation of kinetic energy harvesters, IJRRCS Simulation. Benchmarking and Modeling of Systems and Communication Networks, pp. 1-8.

Anyılmaz M.S., 2006. Design Of Experiment And an Application for Taguchi Method in Quality Improvement Activity, M.S. Thesis, Dumlupinar University, Turkey.

Aouici, H., Yallese, M. A., Chaoui, K., Mabrouki, T., \& Rigal, J. F. 2012. Analysis of surface roughness and cutting force components in hard turning with CBN tool: Prediction model and cutting conditions optimization. Measurement, Vol. 45, No.3, pp. 344-353.

Asilturk Ilhan, Neseli Suleyman, 2012. Multi response optimization of CNC turning parameters via Taguchi Method-based response surface analysis, Journal of Measurement, Vol. 45, pp.785-794.

Chinchanikar, S., \& Choudhury, S. K. 2015. Machining of hardened steel-Experimental investigations, performance modeling and cooling techniques: A review. International Journal of Machine Tools and Manufacture, Vol. 89, pp. 95-109.

Correia A.E., Davim J.P., 2011. Surface roughness measurement in turning carbon steel AISI 1045 using wiper inserts, Journal of Measurement, Vol. 44, No. 5, pp. 1000-1005.

Dambhare, S., Deshmukh, S., Borade, A., Digalwar, A., \& Phate, M. 2015. Sustainability issues in turning process: A study in Indian machining Industry.Procedia CIRP, Vol. 26, pp. 379-384.

Doman D.A., Warkentin A. and Bauer r. 2006. "International Journal of Machine Tools \& Manufacture", Vol. 46, pp. 343-352.

Gaitonde V.N., Karnik S.R., Faustino M., Davim J.P., 2009. Machinability analysis in turning tungsten-copper composite for application inEDM electrodes, Int. J. Refract. Metals Hard Mater, Vol. 27, pp. 754-763.

Kathleen M.C., Natalia Y.K., Jeff R., 2004. center for computational analysis of social and organizational systems (CASOS), Technical Report.

Kaymaz I., McMahon C.A., 2005. A response surface method based on weighted regression for structural reliability analysis, Journal of Probabilistic Engineering Mechanics, Vol. 20, No. 1, pp. 11-17.

Latha B., Senthilkumar V.S., 2010. Modeling and analysis of surface roughness parameters in drilling GFRP composites using fuzzy logic, Journal of Materials and Manufacturing Processes, Vol. 25, No. 8, pp. 817-827.

Liu, D., Huang, C., Wang, J., Zhu, H., Yao, P., \& Liu, Z. 2014. Modeling and optimization of operating parameters for abrasive waterjet turning alumina ceramics using response surface methodology combined with Box-Behnken design. Ceramics International, Vol. 40, No. 6, pp. 7899-7908.

Liu Y.T., Chang W.C., Yamagata Y., 2010. A study on optimal compensation cutting for an aspheric surface using the Taguchi method, CIRP Journal of Manufacturing Science and Technology, Vol. 3, pp. 40-48.

Liveira O., J.F.G., et al.2009. "Industrial challenges in grinding", Annals of the CIRP, pp. 1-18. 
Mahapatra S.S., Patnaik A., Patnaik P., 2006. parametric analysis and optimization of cutting parameters for turning operations based on Taguchi method, in: Proceedings of the Int. Conference on Global Manufacturing and Innovation, pp. 1-6.

Maiyar, L. M., Ramanujam, R., Venkatesan, K., \& Jerald, J. 2013. Optimization of machining parameters for end milling of Inconel 718 super alloy using Taguchi based grey relational analysis. Procedia Engineering, Vol. 64, pp. 1276-1282.

Myers R.H., Douglas C.M., Anderson-Cook C.M., 2009. Process and Product Optimization Using Designed Experiments, 3rd ed., John Wiley \& Sons, Inc.

Palanikumar K., 2010. Modeling and analysis of delamination factor and surface roughness in drilling GFRP composites, Journal of Materials and Manufacturing Processes, Vol. 25, No. 10, pp. 1059-1067.

Park S.H., 1998. Robust Design and Analysis for Quality Engineering, Chapman \& Hall, London.

Rose J Phillip, 2005. Taguchi Techniques for Quality Engineering” Tata Mc Graw Hill 2nd edition.

Ross P.J., 1996.Taguchi Techniques for Quality Engineering, McGraw-Hill Book Company, New York.

Sahoo, A., \& Mishra, P. 2014. A response surface methodology and desirability approach for predictive modeling and optimization of cutting temperature in machining hardened steel. International Journal of Industrial Engineering Computations, Vol. 5, No. 3, pp. 407-416.

Sarıkaya, M., \& Güllü, A. 2014. Taguchi design and response surface methodology based analysis of machining parameters in CNC turning under MQL. Journal of Cleaner Production, Vol. 65, pp. 604-616.

Suhail A.H., Ismail N., Wong S.V., Abdul Jali N.A., 2010. Optimization of cutting parameters based on surface roughness and assistance of workpiece surface temperature in turning process, American Journal of Engineering and Applied Sciences, Vol. 3, No. 1, pp. 102-108.

Sun H., Lee S., 2005. Response surface approach to aerodynamic optimization design of helicopter rotor blade, International Journal for Numerical Methods in Engineering, Vol. 64, No. 1, pp. 125-142.

Wang Z., Meng H., Fu J., 2010.Novel method for evaluating surface roughness by grey dynamic filtering,Journal of Measurement, Vol. 43, No. 1, pp.78-82.

\section{Biographical notes}

Mr. Saurabh Agrawal is a M.Tech. Scholar (Material Handling) in the Department of Mechanical Engineering, Madhav Institute of Technology and Science, India. He is pursuing his thesis work on parametric optimization of CNC Hard Turning.

Dr. Manoj Kumar Gaur is Associate Professor in the Department of Mechanical Engineering, Madhav Institute of Technology and Science, India. He has more than 15 years of experience in teaching and research. His current are of research includes solar thermal, heat transfer. He has published more than 25 papers in referred international journals. He has also presented more than 20 research articles in national and international conferences.

Mr. Dinesh Kumar Kasdekar is Assistant Professor in the Department of Mechanical Engineering, Madhav Institute of Technology and Science, India. His Research interest includes Optimization techniques, CAD/CAM/CAE. He has published various papers in referred international and national journals.

Mr. Sharad Agrawal is Assistant professor in Department of Mechanical Engineering, Madhav Institute of Technology and Science, India. His Research interest includes CAD/CAM, Bio-Structure and Optimization Techniques. He has published various papers in referred international and national journals.

Received March 2015

Accepted May 2015

Final acceptance in revised form November 2017 